\title{
Towards an Integrated Maturity Model of System and E- Business Applications in an Emerging Economy
}

\section{Alejandro Cataldo', César A. Astudillo², Jimmy H. Gutiérrez-Bahamondes ${ }^{3}$, Luis González-Martínez", Robert McQueen ${ }^{5}$.}

\footnotetext{
1 Universidad de Talca, Faculty of Engineering, Business System School, Talca, Chile, acataldo@utalca.cl ${ }^{2}$ Universidad de Talca, Faculty of Engineering, Computer Science Department, Curicó, Chile, castudillo@utalca.cl 3 Universidad de Talca, Faculty of Engineering, Computer Science Department, Curicó, Chile, jgutierrezb@utalca.cl

${ }^{4}$ Universidad de Talca, Faculty of Engineering, Engineering Systems Doctoral Program, Curicó, Chile, luis.gonzalez@utalca.cl

${ }^{5}$ University of Waikato, Department of Management Systems, Hamilton, New Zealand, bmcqueen@waikato.ac.nz
}

Received 16 August 2018; received in revised form 29 April 2019; accepted 8 May 2019

\begin{abstract}
Although there is a great number of maturity models proposed for Information Systems, most of them have three limitations: (1) they are focused on a single or small subset of companies; (2) they do not address the evolution of enterprise systems and e-business applications, simultaneously; (3) they are only focused on developed countries and do not consider emerging economies. We developed a maturity model of Information Systems that addresses these limitations through a data mining approach. The results showed that clustering analysis was an effective method for discovering similar groups of companies according to the set of enterprise systems and e-business applications that they adopted. Two major conclusions can be outlined: Unlike previous models, it has been shown that companies can be grouped only in three stages of maturity. Furthermore, the evolutionary pattern of systems adopted by companies follows a path oriented to obtain greater efficiencies at the expense of those that strengthen the relationship with customers. The results are relevant to practitioners, researchers and policy makers in emerging economies.
\end{abstract}

Keywords: Information systems, Business systems, E-Business applications, Maturity models, Clustering analysis, Data mining 


\section{Introduction}

The idea that social systems evolve similarly to biological systems has been on the minds of great thinkers for over a century. Different theories have contributed to this vision such as Darwin's The Origin of Species and Marx's Das Kapital [28]. In this sense, the theory of information systems (IS) has not been indifferent to this progressive vision of organizational systems. In fact, for over 50 years, many researchers have proposed maturity models to explain the progress stages of some IS within organizations [15], [44].

However, although there is a large number of maturity and stage models proposed in the literature, most of them have three important limitations that motivated this investigation.

First, most studies are focused on a single or small subset of companies, restricting their usefulness to circumstances beyond the organization or system studied (for example, [1]). Second, these models do not address the evolution of enterprise systems (ES) and e-business applications (EA) altogether [8], [29]. Third, the existing models evidence a bias towards developed economies; however, the adoption and implementation of the system in developing countries are affected by different factors [35], [41].

In order to overcome the above-mentioned limitations, we proposed the Integrated Maturity model of Business systems and E-business applications (IMBE). Unlike previous methods, the IMBE is based on data from a developing country, considering factors such as the size of the organization, industry, among others. The IMBE model allows the analysis of the evolution of an organization by identifying its current stage of maturity and considering a set of enterprise systems (ES) and e-business applications (EA), simultaneously. To design IMBE, we clustered the adoption of six typical ES and twelve EA in Chilean companies that responded to a national questionnaire run by the Chilean government. This nation is considered an emerging economy because its economy consists of relatively low, but fast-growing per capita income, and with an administration that is dedicated to economic liberalization [35].

In addition, we applied an empirical approach based on cluster analysis. This is a technique for grouping cases (in this case, companies surveyed) into groups having similarities according to some attributes of interest (in this case, the ES and EA used in each company), while at the same time each group is distinguished from others according to those same attributes [6]. We followed a four-step clustering process: data pre-processing; clustering; performance measuring; and validation.

The contributions of the paper are as follows:

1. We propose a general methodology to characterize the stages of acquisition of information technologies.

2. Our solution is based on data selected by the government to identify the main characteristics of a significant group of companies.

3. The study considers 11 types of information technologies that belong to enterprise systems and e-business applications, respectively.

4. The paper details a successful example on how to apply the method to an emergent economy.

5. A three-stage information technology acquisition maturity model is developed and validated.

In this paper, we develop a maturity model based on cluster analysis. The model divides the attributes of each company according to ES and EA type of system. Our assumption is that companies are grouped by similarity according to business systems and e-commerce applications that have been adopted and this grouping represents their stages of maturity.

The remainder of this article is divided into five sections. The second section summarizes the most relevant works related to maturity models in IS and raises the propositions that guided this research. The third section describes the methodology used. The fourth section presents the main results of this work. The fifth section contains the discussion of the results contrasting them with previous research. The sixth section summarizes the conclusions of this work, limitations and future prospects.

\section{Related work}

Stage models are representations of typical patterns that describe stages of development of some kind of organizational capacity [15]. In this regard and as [34] described, stages are conceptual devices that divide a variable representative of a social continuum into discrete categories, and therefore those categories are a simplification of a phenomenon. 
Regarding IS, stage models have been proposed related to information technology, its management or some other aspect of it. An example of the technology type is [14] who proposed a model of four stages to show the evolution of knowledge management systems in law firms. An example of the management type is [2] who presented a model of five stages to manage outsourcing services. Finally, an example of alternative model is [13] whose authors proposed a model of three stages to display how the CIO's role changes during her/his life in the company.

As it can be inferred from the above, the variety of models is extensive. However, there are few empirical studies focusing on the maturity of companies at the time they adopt their systems. In addition, researchers have proposed maturity models for e-commerce and/or e-business applications, but as far as we know, none of those models describes maturity states that blend enterprise systems and e-business applications. Then, we describe some of the main studies into these two mainstreams: maturity models of ES and maturity models of EA.

The literature on the maturity models in IS/IT fields is extensive. Given the space constraints below, we will summarize the works recently published. For them, we searched the Web of science and Scopus databases for articles that included keywords such as maturity model, stage model, stage of growth, or evolutionary model, along with the information systems and information technologies. Our results showed that 17 related articles have been published from 2013 to the present. After reviewing each of these articles, those that did not propose new maturity models were discarded in our review. Finally, 9 articles were revised, Table 1 summarizes those articles and the most recent of them are described below.

Table 1: Summary table of the state of the art

\begin{tabular}{|c|c|c|c|c|}
\hline Article & Focus & $\begin{array}{l}\text { Number } \\
\text { of Stages }\end{array}$ & Design Methodology & Scope/Sample/Validation \\
\hline [39] & $\begin{array}{l}\text { C2C social } \\
\text { commerce }\end{array}$ & Five & $\begin{array}{l}\text { Conceptual based on } \\
\text { literature review and } \\
\text { case studies }\end{array}$ & Seven interviewees \\
\hline [16] & $\begin{array}{l}\text { Readiness of the } \\
\text { company's IT } \\
\text { department for } \\
\text { digital business } \\
\text { transformation }\end{array}$ & Four & $\begin{array}{l}\text { Conceptual based on } \\
\text { Forrester model and } \\
\text { CMM and regression } \\
\text { model }\end{array}$ & 32 Russian firms \\
\hline [19] & $\begin{array}{l}\text { Social customer } \\
\text { knowledge } \\
\text { management } \\
\text { (SCKM) }\end{array}$ & Five & Fuzzy expert system & \\
\hline [31] & $\begin{array}{l}\text { Information- } \\
\text { driven decision- } \\
\text { making process } \\
\text { (DMP) }\end{array}$ & Five & $\begin{array}{l}\text { Conceptual based on } \\
\text { literature review }\end{array}$ & Three Spanish SMEs \\
\hline [9] & $\begin{array}{l}\text { Managing a } \\
\text { social media } \\
\text { business profile }\end{array}$ & Six & $\begin{array}{l}\text { The Solli-Sæther and } \\
\text { Gottschalk (2010)'s five- } \\
\text { step stage modelling } \\
\text { process }\end{array}$ & Irish companies \\
\hline [22] & $\begin{array}{l}\text { Building } \\
\text { information } \\
\text { modeling }\end{array}$ & Four & $\begin{array}{l}\text { Conceptual based on } \\
\text { literature review and } \\
\text { focus group }\end{array}$ & Hong Kong firm \\
\hline [35] & $\begin{array}{l}\text { Industry } 4.0 \text { in } \\
\text { SMEs }\end{array}$ & $\begin{array}{l}\text { Five } \\
\text { stages \& } \\
\text { Three } \\
\text { phases }\end{array}$ & Conceptual & NA \\
\hline [38] & $\begin{array}{l}\text { Sourcing of } \\
\text { information } \\
\text { technology. }\end{array}$ & Five & $\begin{array}{l}\text { The Solli-Sæther and } \\
\text { Gottschalk (2010)'s five- } \\
\text { step stage modelling } \\
\text { process }\end{array}$ & 116 Norwegian organizations \\
\hline [21] & e-government & Four & $\begin{array}{l}\text { Conceptual based on } \\
\text { literature review }\end{array}$ & NA \\
\hline
\end{tabular}

The author of [39] proposed a maturity model for C2C social commerce or C2C s-commerce. According to authors, the model may help stakeholders understand and assess how mature and well conducted their business processes are. The authors did a review of the related literature, combining different models of maturity and refining the model by seven case studies.

Recently, [16] developed a model to quantify the readiness of the company's IT department for digital business transformation. Authors proposed a four-stage model corresponding to the levels of digital maturity of the company developed by Forrester and correlated with the levels of the standardized CMM model: researchers, beginners, advanced and innovators. In order to measure the maturity level, the model was developed in the form of a 
questionnaire and consisted of 29 questions on seven perspectives. The questionnaire was tested in two groups of firms: 22 firms to calibrate a regression model and 10 firms in a second iteration to validate it.

In addition, [19] presents a SCKM maturity model based on the distribution of critical success factors. According to the authors, understanding the SCKM maturity level makes organizations aware of social media. They proposed a fivestage model: initial, repeatable, defined, managed and optimized. The model was built following a four-step process. Its method was based on a mixed approach that combined literature review, classification and pruning of critical success factors (CSFs), and implementation of a Fuzzy expert system.

In another study, a maturity model called Chroma is presented [31] Chroma was designed to evaluate and determine the level of organizations regarding their competence, readiness and maturity in the use of information to support decision-making. Authors posit that an appropriate use of data will lead firms to more objective and better supported decisions. The model assesses the maturity of a company based on five dimensions and proposes five stages: uninitiated, awareness, proactive adopting, integral embracement and completely embedded. Dimensions and their attributes were selected based on a literature review. A pilot was conducted in three small firms to test the model.

The paper [9] presented a model of growth for managing a social media business profile. They proposed a six-stage model: exploration, experimentation and learning, direction and coordination, formalization, consolidation and integration, and institutional absorption. In the construction of their model, the authors followed the guide suggested by [36] and used a mixed method that began with the conceptual design of the model and its validation in 103 Irish companies and a field study in 10 organizations.

\subsection{Maturity Models of Enterprise Systems}

Perhaps the most known existing maturity model is Nolan's [28]. He studied the evolution of IT budgets of three companies and noted that these grew following a type-S curve. Nolan found that when companies adopt IT, they evolve following a sequential pattern of four stages that he called: Initiation, Contagion, Control and Integration. Nolan later expanded his model adding two new stages Data Administration and Maturity [29]. Nolan's model may be viewed as seminal, given the influence it has had on both theory and practice [11].

The authors of [11] proposed a bi-dimensional matrix as stage model. According to authors, companies evolve following a six-stage pattern, but each with its particular set of conditions associated to seven characteristics of management. These six stages are: Ad-Hocracy Starting the foundations; Centralized dictatorship; Democratic dialectic and cooperation; Entrepreneurial opportunity; and Integrated harmonious relationships. Despite the years, this model remains as one of the most complete descriptions of the evolutionary pattern that companies follow.

Another important model is the Business-IT Alignment Maturity Model by [24]. This author developed a model to evaluate and measure the alignment between business goals and IT companies. Luftman presented a maturity model of five stages: Initial/AdHoc Process; Committed Process; Established Focused Process; Improved/Managed Process; and Optimized Process. Each of these stages can be distinguished using six criteria about the relationship between IT and business.

The IT Value Hierarchy (ITVH) was proposed in [42] using Maslow's Hierarchy of Needs as a base. To develop their model, Urwiler and Frolick mapped every need described by Maslow and defined an equivalent stage for ITVH. Thus, Infrastructure and connectivity needs is the analogous stage for Physiological needs; Stability and security needs is for Safety needs; Integrated information needs is for Social needs; Competitive differentiation is for Esteem needs; finally, Paradigm shifting is the mapping for Self actualization. Obviously, ITVH is a maturity model of five stages. ITVH does not require that all companies must evolve from an initial stage to the highest stage, but assumes lower needs that have been met before the needs of higher stages.

Although experience shows that maturity models can become a tool with high practical value, like Capability Maturity Model (CMM) and Capability Maturity Model Integration (CMMI), many of the previously proposed models have little real value to practitioners. Indeed, several authors have criticized the usefulness of the some of these models [15], [36], [44]. They suggest that developers have followed mainly a conceptual approach rather than an empirical one, and also observe that little empirical validation of the models has been developed. This conceptual bias was also found in our own review of the literature.

Beyond the methodological design approach of the existing models, another important limitation is their narrow scope because of high specificity. Indeed, most of the proposed models are strongly dependent on the organizational context or system. An example of the high degree of specificity of some models of IS adoption is [45], who proposed a model to describe the different stages of training of information security courses.

The models of Nolan, Luftman, and ITVH are an important exception to the rule described above. These three models attempt to describe the stages of maturity of all ES that are used in an organization independent of a specific type of system or a particular context. However, these latter models also have limitations. Despite Nolan's model has made an important contribution to the body of knowledge of IS, its validity has also been questioned. The authors of [23] showed that the IT budget was not an adequate predictor of the stages of evolution of IT into organizations. They 
demonstrated that a better indicator was the increase in IT budget and did not necessarily follow a Type-S curve. Although [23] confirmed the existence of evolutionary processes in IT adoption in organizations, they suggested that the characteristics of Nolan's model should be changed. Thus, in the stage of Initiation, they suggested that organizations acquire computers and transactional systems; in the stage of Contagion, firms implement operational and managerial applications; in the stage of Control, companies adopt integrated database applications; finally, in Integration, organizations acquire decision support systems and strategic applications.

On the other hand, Luftman's model and ITVH do not provide a direct and simple way to evaluate the current stage of maturity of IT adoption of an organization, reducing their utility. Indeed, in the case of Luftman's model, the assessment process is complex. It requires the organization to identify its current maturity stage and evaluate the status of each of the six criteria defined by Luftman. Moreover, there are no direct rules to help clearly classify the maturity of the organization. Something similar could be said in the case of ITVH.

\subsection{E-Commerce/E-Business Maturity Models}

Since the introduction of Internet into organizations in the 90's, numerous researchers have developed models of ecommerce/e-business maturity. The authors of [43] have identified the degree of maturity in the implementation of Information and Communication Technology (ICT) in the organizations as one of the key factors in the adoption of electronic commerce. In 2000, [26] developed an integrated maturity model for back-office (i.e. ES) and front-office (i.e. EA) called SOG-e Model. SOG-e is an extension of that model [11], consequently SOG-e is also a model of six stages of maturity. According to these authors, the introduction of back-office and front-office into companies matures separately in the first four initial stages. During this period, the back-office evolves from the stage of Ad-hocracy to democratic dialectic and cooperation's stage. On the other hand, the front-office evolves from the stage of no-presence to Internet commerce's stage. In the fifth and sixth stages (Integrated organization and Extended enterprise, respectively), both the back office and the front-office are integrated and evolve together. The main contribution of SOG-e is that it is the first integrated model (ES and EA) proposed by researchers; however, this model has two relevant limitations: one is its age and the other is the lack of empirical validation [33]

In [5], a maturity model was developed for the adoption of e-commerce in SMEs using a clustering technique. Four stages of maturity of e-commerce being used were found by analyzing data collected from a group of British SMEs: Developers, Communicators, Web presence and Transactors. Developers are currently developing their first ecommerce services. Communicators are using e-mail to communicate with employees, customers and suppliers. Companies at Web presence stage have information-based websites operating and are developing on-line ordering facilities. Transactors have on-line ordering in operation and are developing on-line payment capabilities [6].

Later, the paper presented in [25] also used clustering to develop a maturity model for the adoption of e-business in SMEs. They found three stages of adoption. Companies in stage 1 devoted little attention to the activities of e-business. Companies in stage 2 might be in a transitional situation. In contrast, firms in stage 3 are the most mature. They found that service firms had a higher maturity status than manufacturing firms.

In [30], the TOE framework (technology, organization and environment) and cluster analysis were used to find companies patterns of e-business adoption. By using microdata from 6,964 European firms, four distinct groups of ebusiness adoption were found. The first group, lowest e-business adoption, had the lowest level of technology readiness; their expected benefits of e-business are the lowest, but they had the highest level of Internet penetration index. The second group, medium e-business adoption with technology integration, were companies making some use of integrated technologies and most of them are improving their products or internal processes. In the third group, medium e-business adoption with high competitive pressure, all firms were facing competitive pressure, despite all of them had the lowest index of technology integration and a low level of technology readiness. In the fourth group, highest e-business adoption, companies were found to have high levels of all variables, except for the Internet penetration [30].

The authors of [7] criticized the existing models by accusing them of being linear, techno-centrist and mechanistic. They claimed firms often follow a discontinuous path concerning technology adoption instead of a linear, stage-bystage progression. Then, they designed a non-linear stage model for e-business in SMEs. The model includes four levels that authors defined based on interactions in the exchange of information between a firm and its suppliers, customers and employees [7]. The model is non-linear because stages can follow a non-sequential path.

\subsection{Limitations of Current Models}

In spite of the agreement that there are many differences between IT adoption in developed and developing economies, research on maturity models is dominated by the context of developed economies [35]. Systems adoption in developing economies is much more difficult due to a much higher turbulence in the companies and their environment [35], [41]. However, some authors do address the differences that may be present in emerging economies [18]. For example, [33] conceptualised an evolutionary model of four stages for Argentine SMEs. In the first stage, firms begin incorporating the software for the accounting function and then spreading the adoption of the software to other 
administrative sectors. According to these authors, companies acquire the software first for the commercial function and later acquire technologies for the tasks of production and technological improvements.

In summary, although there is an abundance of maturity models in IS theory, there are relatively few models for emerging economies, and those built for developed countries are not able to be effectively used in developing countries. This means that there is tremendous opportunity for research dealing with IT adoption and maturity models specifically for developing economies [35].

The works proposed in [6], [25] have two distinct advantages over other maturity models. First, they provide a direct and simple way to assess the stage of maturity of an organization. Second, both research projects were inductive in nature, because researchers determined the number of stages of the model as a result of the clustering process. In other words, they did not initially pre-set the number of stages of their models. However, both works are confined only to e-commerce and their results may not be directly applicable to the case of the adoption of EA.

\section{Methodology}

In this work, Data Mining was used to analyse data that were obtained from a national survey conducted in Chile. Data mining aims to manipulate data so as to discover hidden patterns and knowledge, and it has been successfully used in electronic commerce research [3] [5].

For the sake of clarity, this section has been divided into two subsections. The first subsection describes the dataset and the clustering analysis used, while the second one summarizes the validation and the corresponding results.

Dataset, the data used in this study were downloaded from a governmental website (Site 1). Where, ELE4 is a survey by the Chilean Government of 8084 companies conducted in 2015. The survey consists of 650 closed questions and was grouped into five sections that include aspects such as: financial situation of the company, human resources management, type and number of customers, among others. The survey was conducted by the Instituto Nacional de Estadística (National Statistics Institute of Chile) and companies were forced to answer truthfully by law.

The study focused on a single subset of questions included in ELE4, namely, the technology and systems sections. The data is composed by two categories: ten questions that assess the existence of ES in the company, and eleven questions that represent EA used by companies. These questions were answered in the form of a checklist, so the possible answer could be whether zero (the company does not possess such system) or one (the system is present in the company). Table 1 summarizes these questions.

Table 2: Code and description of the selected questions from the ELE4 survey

\begin{tabular}{|c|c|c|c|}
\hline Code & Question ID & Description & \multirow{9}{*}{ 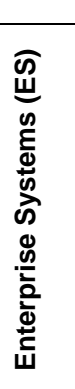 } \\
\hline $\mathrm{J} 010$ & Basic & Basic office software. & \\
\hline J013 & Core & Specific software for bank transfers. & \\
\hline J015 & Sec & Computer maintenance software. & \\
\hline J016 & Non-system & Does not use any software. & \\
\hline J029 & E-govern & Internet - Interact with state agencies. & \\
\hline J051 & Advertising. & Social Networks - Marketing & \\
\hline J055 & Docexch & Social Networks - Innovation of products or services. & \\
\hline J057 & Recruit & Social Networks- Recruitment of workers. & \\
\hline J012 & CCM & Sales, marketing and customer management software. & \multirow{8}{*}{ 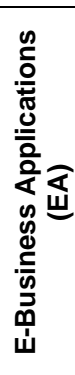 } \\
\hline J025 & Invsuppliers & Internet - Information of goods and services. & \\
\hline J026 & Infosearch. & Internet - Competitor information & \\
\hline J043 & Orders & Website - Sales of products or services. & \\
\hline $\mathrm{J} 044$ & Payment & Website - Pay on line. & \\
\hline J046 & Orderinvent & Website - Transactions to suppliers & \\
\hline J048 & Delivery & Website - Sell online. & \\
\hline J049 & Aftersales & Website - Purchase and sales tracking. & \\
\hline
\end{tabular}

The survey was submitted to the selected companies and the sampling method was stratified in two stages. The first stratification was based on the economic activity of the companies; while for the second, companies were classified by size. The total sample was calculated to obtain a $95 \%$ confidence in representing the whole population of companies. 


\subsection{Data Analysis}

Before analyzing the survey, it is necessary to pre-process the data. This section briefly describes different aspects related to this stage. Specifically, missing values, atypical values, data normalization, dimensionality reduction and other transformations were performed in order to find a final set of data that will be analyzed later using data mining techniques.

The original data set does not contain missing values. However, 223 instances were identified and removed because they presented inconsistencies in the survey responses (the answers only contain zeros, and therefore were considered as incorrect). Furthermore, it is important to note that the data set was conformed by binary attributes, i.e., whose only possible values were zeroes or ones, and therefore no scaling method was required. The first four columns of the original dataset included nominal attributes that were removed during the pre-processing phase. In addition, the Non-System attribute was removed from the dataset because of the low variance.

Clustering Analysis, in order to evaluate the tendency to form clusters, we used the Hopkins statistic [20] by measuring the probability that a given data set is generated by a uniform data distribution. A value higher than 0.5 indicates that the data set has a structure that allows the creation of clusters. The result of this analysis was 0.64 , suggesting that the data tend to form clusters.

As to define the optimal number of clusters, the following 17 indices have been calculated [4]. The indices are the following: KL, Hartigan, CCC, Scott, Marriot, Tr-CovW, TraceW, Friedman, Rubin, Cindex, DB, Silhouette, Ratkowsky, Ball, PtBiserial, Dunn and SDindex. Figure 1 shows the estimated number of clusters for each of the indices. The results have been sorted in descendent order. From Fig. I, it is possible to determine that the majority of the evaluated indices (47\%) establish that the optimum number of clusters is 3.

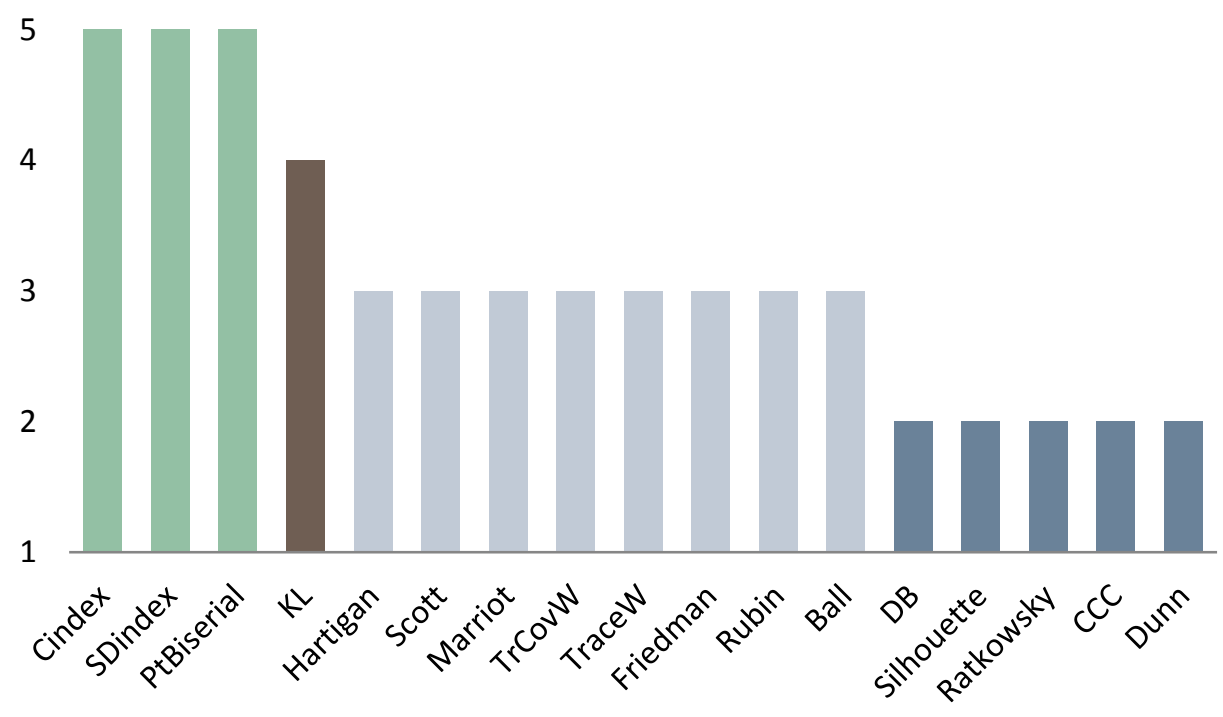

Figure 1: Optimal number of clustering

\subsection{Clustering Methods Tested}

Our proposal is analogous to the Two-Step Cluster Analysis presented in [33]. As the name suggests, the clustering process is achieved in two stages. During the first stage, the data is clustered forming the so-called pre-clusters. In our case, the Self-organizing Maps (SOM) [17] algorithm was selected. We applied a 10x10 SOM grid, because we want to divide the dataset in many subsets, and in a further step, we can control the resultant number of clusters by grouping the neurons. Moreover, SOM is a prototype-based method, and so it produces clusters based on hyperspheres. By enforcing the creation of many small hyper-spheres, the model is able to learn more complex data distributions as the one under scrutiny. Also, the SOM has the desirable property of topology preservation, which means that it can accurately represent complex data distributions using a grid representation. Following this procedure, each company was assigned to one of the neurons that made up the network.

In the second step, the pre-clusters are then grouped according to their similarity, creating the so-called super-clusters. At this juncture, the SOM neurons are grouped together into three super-clusters. We tested several methods for clustering the data. The methods are: K-Means, Hierarchical Clustering, Partitioning Around Medoids (PAM), the Selforganizing Tree Algorithm (SOTA), CLARA and Model-Based Clustering. To measure the quality of the clusters, we used the Connectivity [14] and Dunn [10] indices. 
Table 3 shows the Connectivity and Dunn indices for several clustering methods. For the connectivity index the smaller the best, while Dunn index should be maximum. Hierarchical Clustering showed the best results in both indices

Table 3: Comparison of clustering algorithms for the second step of the clustering process.

\begin{tabular}{|l|l|l|}
\hline Algorithm & Connectivity & Dunn \\
\hline Hierarchical & $\mathbf{9 1}$ & $\mathbf{0 . 1 4}$ \\
\hline K-means & 1117 & 0.05 \\
\hline PAM & 1114 & 0.04 \\
\hline SOTA & 1599 & 0.04 \\
\hline CLARA & 1204 & 0.06 \\
\hline Model-Based Clustering & 1246 & 0.06 \\
\hline
\end{tabular}

In summary, our method found evidence that the data have a tendency to be grouped. The method also finds robust evidence that there are three clusters present in the data. Subsequently, a two-step clustering algorithm was applied in order to find the three clusters. This grouping scheme was based on the sequential application of the SOM and the hierarchical clustering methods.

\section{Results}

Once the clusters have been formed, we built the parallel coordinate plot for the centers of each cluster (see Figure 2). The parallel coordinate plot shown in Fig.II allows to pictorially compare the three clusters by visual inspection. In the plot, each value of the x-axis represent one of the 22 attributes under scrutiny. From this point, it is assumed that the companies that belong to a cluster have characteristics similar to the center of this cluster.

As seen in Figure 2, three clusters were found to follow a sequential pattern. It could be interpreted that companies were grouped by stage of incorporation of ES and EA.

At the initial stage, Cluster 1, companies incorporated almost exclusively basic desktop systems (Basic) and no EA. Then, Cluster 2 grouped companies that had adopted basic systems and had created a webpage. Furthermore, those companies had begun incipiently to use management and security software. Finally, in the third group, Cluster 3 , companies adopted more sophisticated systems: management, security and specialized software for the core of business. Moreover, some of those companies also use SCM and CCM. Regarding EA, companies in Cluster 3 intensively use website to offer products/services and sharing.

Cluster 1 (Basic desktop software): This group includes 2748 organizations and presents the lowest level of acquisition of ICTs. Most of the companies in this group only have basic desktop software such as word processors, spreadsheets, browsers and email. About $85 \%$ do not have a website. Less than $20 \%$ of this group uses social networks to carry out marketing strategies or integrate staff into their teams. However, it is interesting to note that approximately $60 \%$ of the companies use the Internet to contact customers and suppliers.

Cluster 2 (Web-based technology): 1973 companies have been allocated in this cluster. The organizations that were assigned to this cluster have an intermediate level of acquisition of ICTs. Most of them use desktop software. This group presents a notable advantage over cluster 1 , due mainly to the fact that $100 \%$ of these companies have created a website that they use at least to make the details of their products available to the market.

However, they still do not use online services to manage their purchase, sale, distribution and payment operations. In addition, about $30 \%$ of them use social networks to carry out marketing tactics and around $15 \%$ to attract workers.

Cluster 3 (Complex systems): This cluster is the largest and is made up of 3140 organizations. This is the group of companies with an advanced ICT adoption degree. Practically all of them use desktop software. Similarly to group 2 , all the companies have a website. They are characterized by using software to support the management of a large part of their operations, especially in the interaction with clients. Despite having an intensive use of ICTs, less than $50 \%$ use online sales, purchase, payment and distribution services. They present a significant increase in the use of social networks with respect to the rest of the groups identified in this study, where approximately $70 \%$ of the companies within this group promote their marketing strategies through this type of technology.

The data analyzed considered companies from 13 different economic activities. In order to identify patterns that characterize the different stages of evolution in the adoption of ICTs, Figure 3 shows the total of companies assigned in each cluster according to the type of activity. 


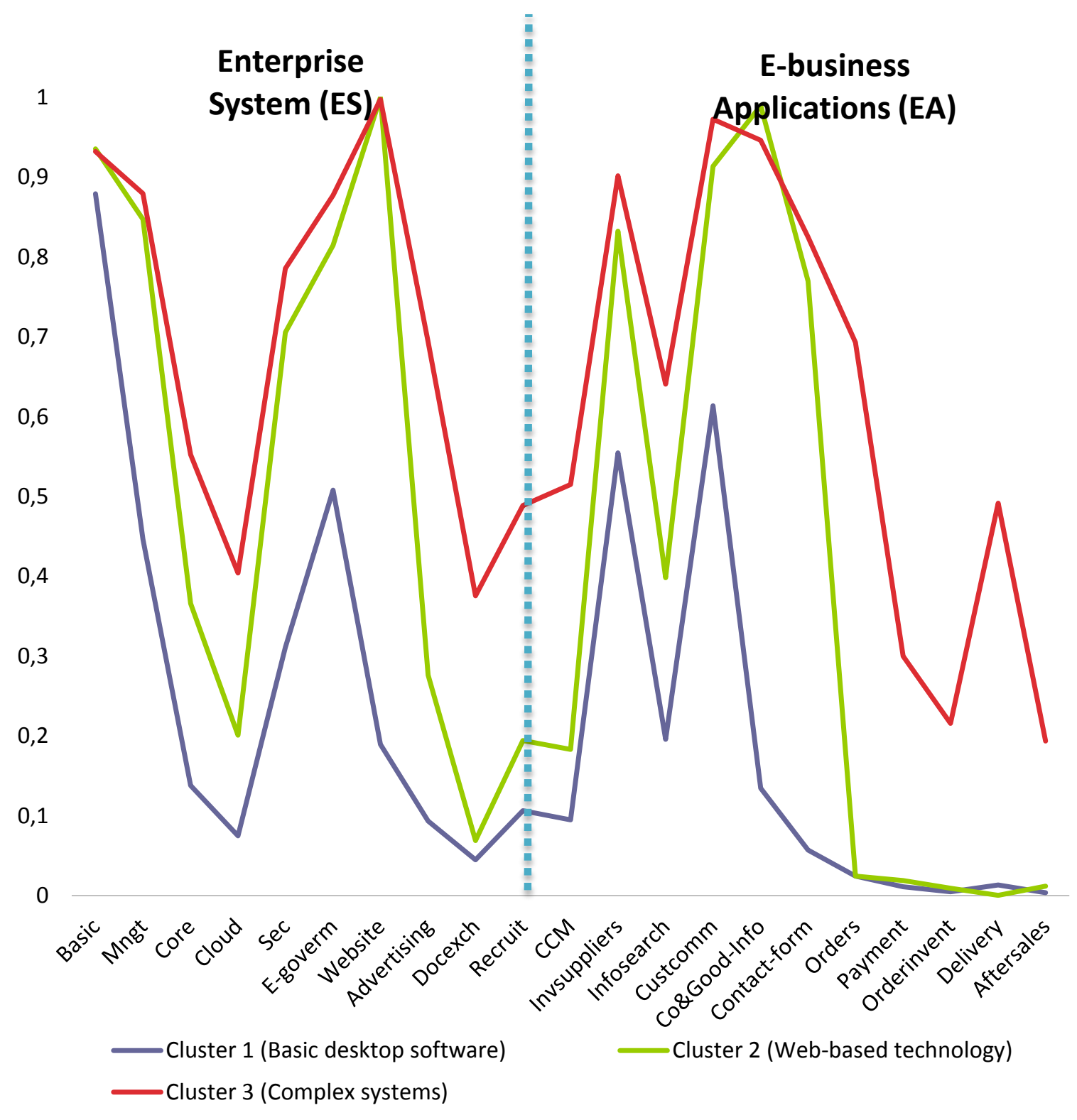

Figure 2: Coordinate map of the three clusters found 
Transportation and Storage

Supply of electricity, gas and water

Other services

Information and Communications

Manufacturing industries

Exploitation of Mines and Quarries

Building

Wholesale and Retail

Agriculture, forestry and fishing

Professional, scientific and technical activities

Financial and insurance activities

Service activities

Accommodation and meal service activities

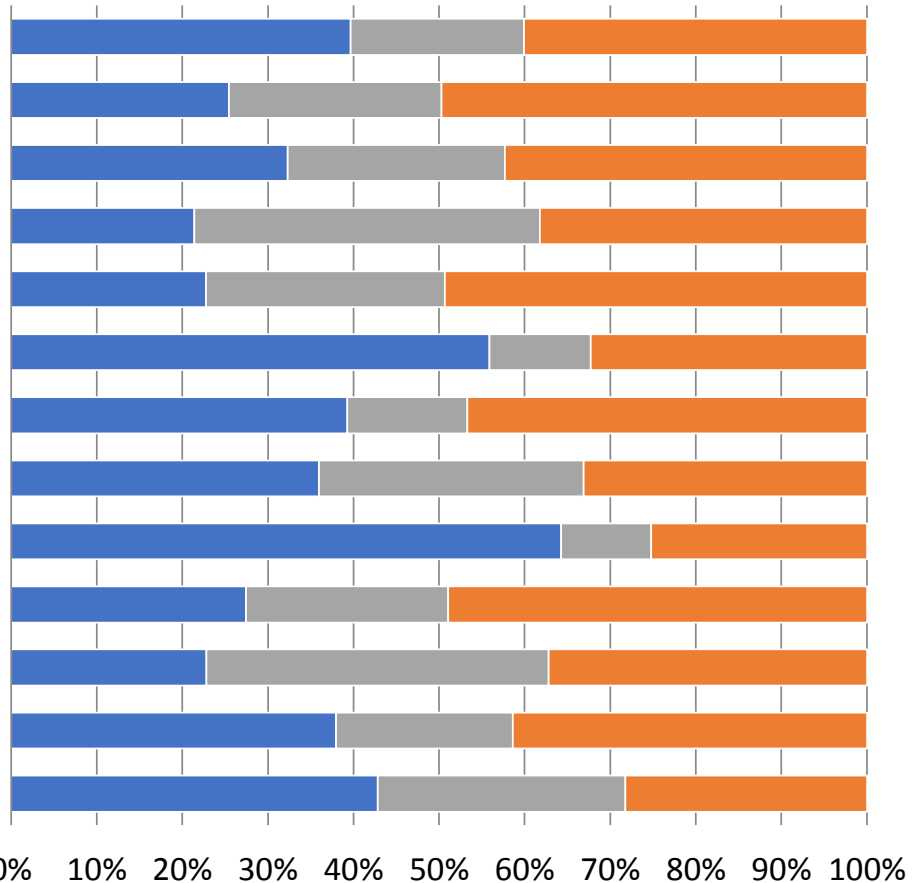

- Cluster 1 - (Basic desktop software) Cluster 2 - (Web-based technology)

- Cluster 3 - (Complex systems)

Figure 3: Companies assigned in each cluster.

We observe that companies belonging to activities related to the generation of primary products such as agriculture, mining, fishing and mineral extraction are concentrated in cluster 1 . This type of institutions are primarily assigned to cluster 1, and show a low presence in the intermediate stage (cluster 2) and an even smaller presence in the cluster 3. On the other hand, companies related to technological, scientific and manufacturing activities, where highly qualified personnel are required, are mainly concentrated in cluster 3 . However, the rest of the organizations with similar characteristics are allocated equally among clusters 1 and 2.

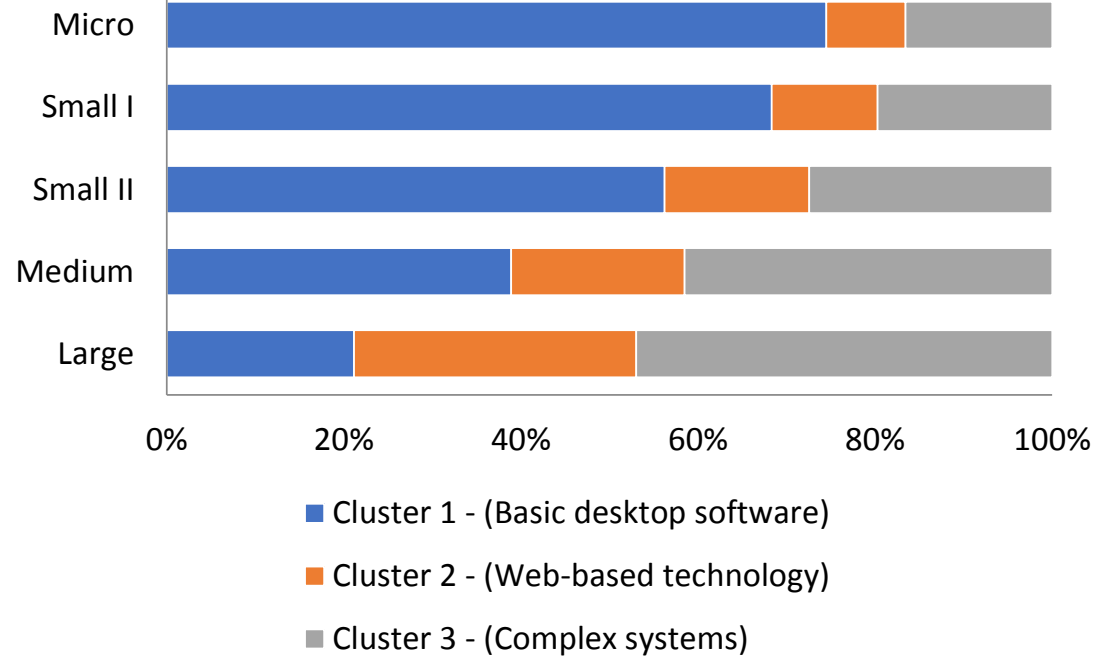

Figure 4: Companies grouped by size

Five annual sales sizes were defined in Unidad de Fomento (UF): Large (over 100,000,01 UF), Medium (between 25,000.01 UF and 100,000 UF), Small 2 (between 5,000,000 UF and 25,000 UF), Small 1 (between 2,400.01 UF and 5,000 UF) and Micro (between 800,01 UF and 2,400 UF). 
As it is possible to see in Figure 4, the smaller companies are grouped mainly in cluster 1. On the opposite side, large companies are distributed mainly in clusters 2 and 3 . However, it is surprising that about $20 \%$ of them are still in an initial stage of the acquisition of information technologies (cluster 1).

\section{Discussion}

The three-stage model is not consistent with most of the research on maturity models [10] and models similar to IMBE [6], [23] that raise 4 groups. This is mainly because our research reveals that there are no companies without any adoption of information technology. This is why the first cluster presented in previous research has disappeared.

Regarding ES, previous research seems to confirm the pattern of adoption that has been found. In fact, our model is consistent with other models regarding that after the basic systems, companies tend to adopt applications to improve administrative management [25], [29], [33], [42]. Notably, IMBE fits with the first three stages of Nolan's model as modified by [23] and with Swanson's Three-core model [40]. Since these models were developed more than 20 years ago, this coincidence could indicate that the surveyed companies have a gap with those thought by [23].

The integrated model, i.e. ES and EA, shows that Chilean companies register websites early after starting to computerize their infrastructure. However, the real online presence does not occur until the third stage. Moreover, even companies at the highest level of e-business maturity have low levels of EA use. The main e-business applications that Chilean companies use are focused mainly on promoting their products/services and improving the internal efficiency of the company. The model also shows that Chilean companies pay little attention to creating interactive sites or building websites focused on improving relationship with the customer.

In a developing economy's context, IMBE shows partial similarities with other models. [33] model coincides with the first stage of IMBE. However, the subsequently pattern of progress suggested by IMBE was opposite to the one described by those authors i.e. after initial adoption, companies begin to acquire software for the commercial function and, ultimately, technologies for the tasks of production and technological improvements.

This shows a gap and delay of the Chilean companies with respect to the evolution followed by companies of developed countries. For example, studies by [6], [25] showed that British companies had already adopted e-business applications that Chilean companies currently do not incorporate yet. In fact, the most advanced stages of e-business found in Chilean companies, Supporting and Integration, are equivalent to the three lower levels found by [6] (Developer, Communicators, and Web presence). Moreover, Chilean companies do not yet reach the highest level of maturity defined by [6], Transactors. This result is surprising because this comparison is given in a study of more than ten years ago.

The lack of interest shown by Chilean companies to develop more complex and interactive websites that strengthen the relationship with their customers is a pattern also found at the domain of business systems. Actually, this result is in line with the evolution followed by ES. The model shows that most of Chilean companies acquire systems that strengthen internal efficiency (Mngt, Sec and Core) at the expense of systems that help improving customer relationships or support the front-office (CCM).

The evolutionary pattern of ES and EA adopted by Chilean companies follows a path oriented to obtain greater efficiencies at the expense of those that strengthen the relationship with customers. Comparatively, this has caused Chilean companies to be more than ten years behind in their adoption of customer-focused systems than those from developed countries.

Using the results obtained in this study, researchers and policymakers will be able to make decisions from different points of view. Within the context of Information and Communication Technologies (ICTs), they will be able to clearly identify the characteristics of the three stages in which companies evolve. Unlike different studies reported in the literature, our focus is placed on an emergent economy, and the results of the analysis could be used in the future to make a comparison with the evolution of developed countries.

From an inner perspective of the company, the decision makers must identify the stage in which the company is and generate strategies that allow them to advance to the next level of maturity. We have identified that the main difference between the group of companies with the earliest adoption of ICTs and the next group is the intensive use of web technology for the promotion of their products. Moreover, the first cluster of companies is characterized by a lack of technological tools to facilitate communication with the market. Also, organizations identified in the second group evidence high similarity with the group with the most advanced adoption of ICTs. However, the third group adopts more complex technologies for managing operational activities such as payment, delivery and transactions with their suppliers. Likewise, the most advanced group shows a high contrast in the use of social networking systems, which is particularly relevant in the purchasing and selling services. Finally, the most complex group still needs to fully develop cloud technologies, as well as social networking and after-sales services.

On a different perspective, ICT providers can use the results described in this research to develop marketing strategies based on customer segmentation. Therefore, it will be possible to identify the necessities of the companies as they 
evolve, gaining a better understanding of their clients, developing more efficient promotional campaigns, identifying opportunities and new market niches, offering specialized training programs, among others.

Based on the reasonable assumption that all owners desire the growth of their companies, the cluster analysis presented in this work establishes the foundation of a new methodology to generate a maturity model that provides valuable information for all the actors interested in this area.

\section{Conclusions}

In summary, two major conclusions can be stated. First, companies can be grouped into three stages of maturity according to the ES and EA that they have adopted. The stages found follow a sequential progression of three levels. In the most basic stage, there are companies that have incorporated only basic desktop systems (Basic). In the second stage (Supporting), there are companies that have also acquired administrative and security systems, in addition, they all have already a website and promote their products/services through the Internet. In the upper stage (Integration), there are companies that have adopted all previous software and a specialized system; also all of these companies have a website that is used for a basic interaction with customers: promote products, contact form and FAQ.

A second conclusion is related to the evolutionary pattern of ES and EA followed by Chilean companies. The resultant maturity model shows that Chilean companies have chosen to use ES and EA as to improve their efficiency at the expense of technologies that increase customer relationships. Compared with similar models from developed countries, this result would show that Chilean companies are lagging behind in several years. We can speculate that this occurs because of the structural differences between firms in emerging nations like Chile and developed country companies: the former would choose strategies focused on efficiencies, while the latter would focus on customers. More research is needed to deepen this result.

Because of the data used and the context in which it was collected, three limitations must be recognized in this research. First, although the set of six applications used in the dataset represents the most commonly found in companies, other applications were excluded, especially those related to internet services such as websites or cloud computing. This opens the possibility of extending MMIS to include a greater set of IT use categories. Second, the data used were provided by a government entity independent from the academia, which limits the ability to fully understand some of the methodological aspects of the sampling and data collection process. Third, although the set of surveyed companies represents a diverse spectrum of income, sizes and industries, all companies in the sample were Chilean firms, which limit the generalizability of the results to only one national geographic context. Therefore, extrapolation of the findings of this research to new cultural or geographic contexts should be made with caution.

The results of this research are relevant for both researchers and practitioners. For researchers, the findings raise at least two questions that future works could address: (1) What are the triggers that generate addition to the size and type of task? (2) What other contingent factors can influence the stage of maturity of use of ES and EA for companies? For practitioners, the EMBI can be a simple tool to assess the current status of their organization and establish guidelines for progressing to more advanced stages. In addition, EMBI provides a framework for benchmarking, as EMBI can be used as an instrument of comparison with other companies. In addition, EMBI provides guidelines for policy-makers on how to promote adoption of ES and EA into companies.

This work focuses on the ELE4 data and constitutes the first attempt for creating a more robust maturity model that includes ES and EA, simultaneously. The expansion of the data considering complementary information has the potential to produce more complete models. However, this kind of extension goes beyond the current scope of our paper. Future research may consider the expansion factor for each firm in function of any criteria like size, industry, and region, among others.

Another path that can be explored is the application of the proposed method to characterize other emerging and developing economies.

\section{Acknowledgments}

This work was partially funded by the CONICYT PFCHA/DOCTORADO BECAS CHILE/2018 - 21182013.

\section{Websites List}

Site 1: Cuarta encuesta longitudinal de Empresas (ELE4). Ministerio de economía, fomento y turismo de Chile. http://www.economia.gob.cl/estudios-y-encuestas/cuarta-encuesta-longitudinal-de-empresas-ele-4 


\section{References}

[1] J. Avritchir, A. Maturity model foroOffshore insourcing: A research proposal, in Proceedings of the Tenth Americas Conference on Information Systems, New York, 2004, pp. 3488-3492.

[2] B. Bahli, Toward a capability maturity model for the management of outsourcing information services, in Proceedings of the Americas Conference on Information Systems, New York, 2004, pp. 3501-3508, 2004.

[3] J. Basl, Analysis of industry 4.0 readiness indexes and maturity models and proposal of the dimension for enterprise information systems, in Proceedings International Conference on Research and Practical Issues of Enterprise Information Systems, Poznan, Poland, 2018, pp. 57-68.

[4] M. Charrad, N. Ghazzali, V. Boiteau, and A. Niknafs, NbClust: An R package for determining the relevant Number of clusters in a data set, Journal of Statistical Software, vol. 61, no. 6, pp. 2-36, 2014

[5] X. Cui and T. E. Potok. (2005, January) Document clustering analysis based on hybrid PSO+K-means algorithm. Researchgate. [Online]. Available: https://www.researchgate.net/publication/228623408 Document clustering analysis based on hybrid PSO K-means algorithm

[6] E. Daniel, H. Wilson and A. Myers, Adoption of e-commerce by SMEs in UK, International Small Business Journal, vol. 20, no. 3, pp. 253-270, 2002.

[7] P. Depaoli and S. Za, Towards the redesign of e-Business maturity models for SMEs, in Designing Organizational Systems (R. Baskerville, M. De Marco and P. Spagnoletti, Eds.). Berlin, Germany: Springer Berlin Heidelberg, 2013, pp. 285-300

[8] R. DePietro, E. Wiarda and M. Fleischer, The context for change: Organization, technology and environment, in The Processes of Technological Innovation (L. G. Tornatzky and M. Fleischer (Eds.). Lexington, MA: Lexington Books, 1990, pp. 151-175.

[9] A. Duane and P. O'Reilly, A conceptual stages-of-growth model for managing a social media business profile, The Irish Journal Management, vol. 36, no. 2, 2017.

[10] J. C. Dunn, Well-separated clusters and optimal fuzzy partitions, Journal of Cybernetics, vol. 4, no. 1, pp. 95-104, 1974.

[11] R. Galliers and A. Sutherland, Information systems management and strategy formulation: The stages of growth model revisited, Information Systems Journal, vol. 1, no. 2, pp. 89-114, 1991.

[12] J. Ganzarain and N. Errasti, Three stage maturity model in SME's towards industry 4.0,Journal of Industrial Engineering Management, vol. 9, no. 5, pp. 1119-1128, 2016.

[13] A. Gorgeon, Evolution of the role of change agent for ClOs during their time in office, in Proceedings of the International Conference on information Systems (ICIS), St. Louis, MO, 157, 2010, pp. 1-20.

[14] P. Gottschalk, Toward a model of growth stages for knowledge management technology in law firms, Journal of Computer Information Systems, vol. 5, no, 2, pp. 79-93, 2002.

[15] J. Handl, J. Knowles and D. B. Kell, Computational cluster validation in post-genomic data analysis, Bionformatics, vol. 21, no. 15, pp. 3201-3212, 2005.

[16] E. Isaev, N. L. Korovkina and M. S. Tabakova, Evaluation of the readiness of a company's IT department for digital business transformation, Business Informatics, vol. 2, no. 44, pp. 55-64, 2018.

[17] G. James, D. Witten, T. Hastie, and R. Tibshirani, An Introduction to Statistical Learning (Vol. 103). New York, USA: Springer New York, 2013.

[18] G. F. Khan, J. Moon, C. Rhee, and J. J. Rho, E-government skills identification and development: Toward a staged-based user-centric approach for developing countries, Asia Pacific Journal of Information Systems, vol. 20, no. 1, pp. 1-31, 2010

[19] B. Lak and J. Rezaeenour, Maturity assessment of social customer knowledge management (Sckm) using fuzzy expert system, Journal of Business Economics and Management, vol. 19, no. 1, pp. 192-212, 2018.

[20] R. Lawson and P. C. Jurs, New index for clustering tendency and its application to chemical problems, Journal Of Chemical Information And Computer Sciences, vol. 30, no. 1, pp. 36-41, 1990.

[21] R. Lechakoski and D. F. Tsunoda, Proposta de um modelo de maturidade para sítios de governo eletrônico, AtoZ Novas Práticas em Informação e Conhecimento, vol. 4, no. 1, pp. 43-54, 2015.

[22] C. Liang, W. Lu, S. Rowlinson, and X. Zhang, Development of a multifunctional BIM maturity model, Journal of Construction Engineering and Management, vol. 142, no. 11, p. 06016003, 2016.

[23] H. Lucas and J. Sutton, The stage hypothesis and the S curve: Some contradictory evidence, Communications of the ACM, vol. 20 , no. 4 , pp. 2-7, 1977.

[24] J. Luftman, Assessing IT-business alignment, Communications of the Association for Information Systems, vol. 4 , no. 15 , pp. $2-50,2000$

[25] S. R. Magal, P. Koslage and N. M. Levenburg, Towards a stage model for e-Business adoption among SMEs: Preliminary results for manufacturing and service firms, presented at the AMCIS, Toronto, Ontario, Canada, August 6-9, 2008.

[26] J. McKay, P. Marshall and A. Prananto, Stages of maturity for e-business: The SOG-e model, Paper presented at the Fourth Pacific Asia Conference on Information Systems, Hong Kong, China, June 1-3, 2000.

[27] M. Mora, F. Wang, M. S. Raisinghani, and O. G. Muravchik, The evolution of the business-IT strategic alignment process: key insights and emergent views from a 40-year period (1975-2014), International Journal of Business Information Systems, vol. 25, no. 1, p. 118, 2017.

[28] R. Nolan, Managing the computer resource: A stage hypothesis, Communications of the ACM, vol. 16, no. 7, pp. 399-405, 1973. 
[29] R. Nolan, Managing the crises in data-processing, Harvard Business Review, vol. 57, no. 2, pp. 115-126, 1979.

[30] T. Oliveira and M. Martins, Firms patterns of e-business adoption: Evidence for the European Union-27, The Electronic Journal Information Systems Evaluation, vol. 13, no. 1, pp. 47-56, 2010.

[31] X. Parra, X. T. Martorell, C. R. Viñals, and F. Á. Gómez, CHROMA: A maturity model for the information-driven decision-making process, International Journal of Management and Decision Making, vol. 16, no. 3, p. $224,2017$.

[32] D. Proença and J. Borbinha, Maturity models for information systems-a state of the art, Procedia Computer Science, vol. 100, pp. 1042-1049, 2016.

[33] M. Radovic, O. Ghonima and T. Schumacher, Data mining of bridge concrete deck parameters in the national bridge inventory by two-step cluster analysis, ASCE-ASME Journal of Risk and Uncertainty in Engineering Systems, Part A: Civil Engineering, vol. 3, no. 2, 2017.

[34] E. M. Roger, Diffusion of Innovations. New York: Simon and Schuster, 2003.

[35] N. Roztocki and H. R. Weistroffer, Research trends in information and communications technology in developing, emerging and transition economies, Collegium of Economic Analysis, vol. 20, pp. 113-127, 2009.

[36] H. Solli-Sæther and P. Gottschalk, The modeling process for stage models, Journal of Organizational Computing and Electronic Commerce, vol. 20, no. 3, pp. 279-293, 2010.

[37] H. Solli-Sæther and P. Gottschalk, The modeling process for stage models, Journal of Organizational Computing and Electronic Commerce, vol. 20, no. 3, pp. 279-293, 2010.

[38] H. Solli-sæther, P. Gottschalk and H. Solli-sæther, Stages-of-growth in outsourcing, offshoring and backsourcing: Back to the future?, Journal of Computer Information Systems vol. 55, no. 2, pp. 88-94, 2016.

[39] S. Sukrat, A maturity model for C2C social commerce business model, International Journal of Electronic Commerce Studies, vol. 9, no. 1, pp. 27-54, 2018.

[40] E. B. Swanson, Information systems innovation among organizations, Management Science, vol. 40, no. 9, pp. 1069-1092, 1994.

[41] M. Themistocleous, P. Soja and P. R. da Cunha, The same, but different: enterprise systems adoption lifecycles in transition economies, Information Systems Management, vol. 28, no. 3, pp. 223-239, 2011.

[42] R. Urwiler and M. N. Frolick, The IT value hierarchy: Using Maslow's hierarchy of needs as a metaphor for gauging the maturity level of information technology use within competitive organizations, Information Systems Management, vol. 25, no. 1, pp. 83-88, 2008.

[43] E. Villa, L. Ruiz, A. Valencia, and E. Picón, Electronic commerce: Factors involved in its adoption from a bibliometric analysis, Journal of Theoretical and Applied Electronic Commerce Research, vol. 13, no. 1, pp. 3970, 2018.

[44] R. Wendler, The maturity of maturity model research: A systematic mapping study, Information and Software Technology, vol. 54, no. 12, pp. 1317-1339, 2012.

[45] S. William, The organizational information infrastructure maturity model: Implications for IT professionals, in Proceedings of the Americas Conference on Information Systems (AMCIS), Dallas, TX, 2002, pp. 2163-2168. 